\title{
Short-Term Adverse Effects of Austerity Policies on Mortality Rates: What Could Their Real Magnitude Be?
}

\author{
Cristina Hernández-Quevedo, PhD, MSc \\ Beatriz G. Lopez-Valcarcel, PhD \\ Miquel Porta, MD, PhD, MPH
}

doi: 10.2105/AJPH.2018.304507

August 2018, Vol 108, No. 8 - AJPH - Hernández-Quevedo et al. - Editorial

Assessing the effects of policies on health matters. A lot. It matters in ways as ancient as humanity, and it matters in particularly challenging ways in this age of post-truths, alternative facts, fake news, plain lies, and other expressions of the reluctance to look at reality. Valid scientific studies are crucial in assessing the effects of policies. The article by Cabrera et al. illustrates the importance of looking at the effects of politically and financially driven responses to the economic crisis. Also, their empirical analysis shows the need to assess how economic, fiscal, occupational, welfare, environmental, and sanitary policies have affected the conditions in which citizens work (or not) and live, or die; the performance of health systems; and indicators of population health. ${ }^{1}$

The sharp increase in mortality in Spain from 2010 to 2011 reported by the authors is difficult to attribute to austerity policies because it largely precedes them. With the exception of 2012, public expenditures in Spain increased each year from 2007 to 2015. Social expenditures dropped only 0.1 gross domestic product points from 2010 to $2011 .^{2}$ The main austerity measures - especially those deriving from a Royal Decree Law, in force since July 2012 - were implemented in 2012 and thereafter. $^{3}$

\section{A CHANGE IN THE STANDARD POPULATION}

The putative mortality increase did follow the onset of the economic recession in 2007 and 2008.

Crucially, the reliability of the age-adjusted overall mortality rates (AAMRs) used by Cabrera et al., particularly for 2011, is problematic: the population used to standardize rates changed in 2011 . $^{4}$

Before 2011, the standard population used for AAMRs was the Spanish population of July 1, 1999; since 2011, the European standard population provided by Eurostat has been employed. ${ }^{3}$ Cabrera et al. acknowledge in an appendix that the AAMR data they used are not comparable from 2010 to 2011 because of the change in the reference population; yet, they base their most important calculations on these unreliable data. Hence, their results should be considered with great caution. 
Poverty and impoverishment — and the related lack or loss of social protection and welfare benefitsmay be key in explaining the links between the economic recession, austerity measures, and increasing mortality in Spain and many other countries. The long-term high unemployment rate became even more dramatic in Spain after the onset of the crisis, increasing from $9.2 \%$ in 2005 to $22.1 \%$ in $2015,{ }^{5}$ with the young population (48\% of which was unemployed in 2015 ) particularly affected. ${ }^{4}$ The recession had a stronger impact on the poorest households, with the Gini coefficient (inequality gap) increasing from 32.2 in 2005 to 34.6 in $2015 .{ }^{4}$ Working conditions (physical and psychosocial), environmental pollution, nutritional habits, and other life conditions deteriorated as well. ${ }^{6}$

The inclusion of valid data from more countries and on additional socioeconomic factors could have nuanced or refuted the conclusions of Cabrera et al.; in particular, their conclusion that "the marked excess mortality from 2011 to 2015 in Spain is attributable to austerity policies” (p. 1091).

\section{LAG BETWEEN CRISIS ONSET AND AUSTERITY POLICIES}

In Spain, part of the government's response to the financial crisis entailed a series of measures designed to reduce public spending on health and funding of other social policies. The main reform instrument targeting the health system was the earlier mentioned Royal Decree Law, ${ }^{3}$ which introduced changes in the population covered (nonregistered immigrants were excluded, with exceptions), redefined copayments for drugs according to income levels, and split benefits into four categories with varying degrees of public financial support. The reforms also made households responsible for some of the costs related to health care and pharmaceuticals. Important as these changes were, other fundamental determinants of mortality act beyond such frames.

The supposed excess of mortality attributed by Cabrera et al. to government austerity policies occurred primarily in 2011, before the implementation of restrictions in health care coverage; the maximum lag subsequent to the onset of the crisis was approximately three years only. Copayments increased in July 2012, and public health care funding dropped just 2\% in 2011 but 6\% in 2012.

Could we be seeing a "harvest effect" among citizens at high risk for short-term death, who might have had their life shortened by austerity measures? If this was the case, it would be appalling. Yet, evidence and models of health determinants indicate that, in postindustrial societies, social patterns of mortality are the result of long-term economic, social, and environmental processes; only certain specific causes of death are affected in the short term. Most oncological, cardiovascular, and respiratory deaths are not caused by short-term social processes.

Better data and analyses are needed on the effects of policy alternatives on mortality and related causal processes. However, this need should not be an excuse to delay just and efficient policies. European data show that the gap between the poorest and the richest with respect to health status and lifestyle factors persisted before, during, and after the economic crisis. ${ }^{4}$ Some influences on the gap (e.g., income related inequalities in health) may have worsened in the period of interest, whereas others improved (e.g., income-related inequalities decreased in terms of self-assessed health and increased with respect to certain lifestyle factors). ${ }^{4}$ An evaluation of valid mortality data according to socioeconomic position in a larger number of countries would help to test whether - mediated and unmediated by austerity policies - a broadening of the gap between worse-off and better-off groups caused by the recession had an immediate effect on mortality. 


\section{INFLUENCE OF OTHER FACTORS}

Government choices during financial crises often have disastrous effects on human health and the real economy. However, reality is not only influenced by governments. Politics and social processes are never simple. First, coinciding with Spain's austerity measures, other public health reforms were introduced. In 2010, for instance, a law on tobacco consumption and market regulation extended the provisions of the 2005 Anti-Tobacco Law, increasing protection of minors and nonsmokers. In late 2011, a progressive public health law was approved; although never formally enacted by the conservative federal government, it likely strengthened existing and new policies. ${ }^{7}$ Additional regulations increased taxation of alcohol and tobacco products. Second, regional and local health systems discouraged use of ineffective or iatrogenic medical interventions, a long overdue policy. Unfortunately, waiting lists for and delays in diagnosis and treatment also increased during the recession, and they continue.

A valid analysis of the actual middle-and long-term effects on mortality of these mixed measures and policies - and of the other effects of the socioeconomic corrosion itself-is essential to gain an understanding of the real magnitude of the adverse effects, and to assess whether these effects were partly compensated by healthy social policies and networks. Indeed, we must consider the beneficial effects of the existing welfare state, regional and local governments, other public and private institutions, citizens' organizations, and other health as-sets and networks. The effects of these realities must also be considered when we look at reality. We know that the economic recession has impoverished and harmed many Spaniards and other citizens worldwide, and that it has increased social inequality; however, on the basis of the existing evidence, we honestly cannot say whether austerity policies have yet had a substantial impact on mortality rates.

\section{CONTRIBUTORS}

M. Porta prepared the first draft and subsequent versions of the editorial on the basis of contributions from $\mathrm{C}$. Hernández-Quevedo and B. G. Lopez-Valcarcel. B. G. Lopez-Valcarcel and C. Hernández-Quevedo reviewed all versions and contributed to all revisions of the editorial.

\section{ACKNOWLEDGMENTS}

This work was supported in part by grants from Instituto de Salud Carlos III (FIS PI13/00020, FIS PI17/00088, and CIBER de Epidemiología y Salud Pública), Government of Spain; Research Project ECO2013-48217-C2, Plan Nacional de I+D; Fundació La Marató de TV3 (20132910); and Government of Catalonia (2014 SGR 1012, 2017 SGR 439).

\section{REFERENCES}

1. Thomson S, Figueras J, Evetovits T, et al. Economic crisis, health systems and health in Europe. Available at: http:// www.euro.who.int/_data/assets/pdf_ file/0008/289610/Economic-Crisis-Health-Systems-Health-Europe-Impactimplications-policy.pdf?ua=1. Accessed May 3, 2018.

2. Conde-Ruiz JI,DíazM,Marín M, Rubio-Ramírez J. Sanidad, educación y protección social: recortes durante la crisis [Health care, education, and social protection: cuts during the crisis]. Available at: http://www.fedea.net/documentos/ pubs/eee/eee2016-17.pdf. Accessed May 3, 2018. 
3. Real Decreto ley 16/2012, de 20 de abril, de medidas urgentes para garantizar la sostenibilidad del Sistema Nacional de Salud y mejorar la calidad y seguridad de sus prestaciones [Royal Decree Law 16/2012, April 20, 2012, on urgent measures to guarantee the sustainability of the National Health System and to improve the quality and safety of their benefits]. Available at: https://www.boe.es/boe/

dias/2012/04/24/pdfs/BOE-A-20125403.pdf. Accessed May 3, 2018.

4. National Institute of Statistics. Estadística de defunciones según la causa de muerte: metodología [Mortality statistics by cause of death: methodology]. Available at: http://www.ine.es/daco/daco42/

sanitarias/metodologia_00.pdf. Accessed May 3, 2018.

5. Eurostat. Income and living conditions. Available at: http://ec.europa.eu/ eurostat/web/income-and-livingconditions/data/database. Accessed May 3, 2018.

6. López-Valcárcel BG, Barber P. Economic crisis, austerity policies, health and fairness: lessons learned in Spain. Appl Health Econ Health Policy. 2017;15(1): 13-21.

7. Hernández-Aguado I, Benavides FG, Porta M. Los profesionales españoles de la salud pública ante la Ley General de Salud Pública [Spanish public health professionals and the General Law of Public Health]. Gac Sanit. 2012;26(4): 295-297.

\section{ABOUT THE AUTHORS}

Cristina Hernández-Quevedo is with the European Observatory on Health Systems and Policies, London School of Economics and Political Science, London, England. Beatriz G. Lopez-Valcarcel is with the Department of Quantitative Methods for Economics \& Management, University of Las Palmas de Gran Canaria, Canary Islands, Spain. Miquel Porta is with the Hospital del Mar Institute of Medical Research (IMIM), Universitat Autònoma de Barcelona, CIBER de Epidemiología y Salud Pública, Barcelona, Spain, and the Gillings School of Global Public Health, University of North Carolina, Chapel Hill.

Correspondence should be sent to Miquel Porta, MD, PhD, MPH, Hospital del Mar Institute of Medical Research, Universitat Autònoma de Barcelona, Carrer del Dr. Aiguader 88, E-08003 Barcelona, Catalonia, Spain (e-mail: mporta@imim.es). 